\title{
Laser-guided impact
}

\section{In 1960, no one guessed how great the impact of the laser would be. It's a reminder that the best returns on research funding don't always come from the obvious places.}

The invention of the laser - fifty years ago this month - is, alongside that of the transistor, one of the most significant technological developments of the modern age. Albert Einstein had established the lasing principle as early as 1917, through his work on quantum theory. A series of developments over the next decades culminated in Theodore Maiman's demonstration of the first working laser at the Hughes Research Laboratory, California, on 16 May 1960.

Famously, Maiman's write-up was rejected by Physical Review Letters, whose editors judged it just another episode in the stream of research related to masers, led by Charles Townes and others. Equally famously, the laser was dubbed "a solution looking for a problem" - which Townes has said he regarded not as a joke but as a challenge ${ }^{1}$.

What use could a laser be? In 2010, it's not difficult to come up with plenty of answers to that question. The marrying of optics with electronics opened a broad avenue of exploration in physics and a fast route to technological progress - the story is told in a new supplement, Nature Milestones: Photons, jointly produced by Nature Physics, Nature Materials and Nature Photonics.
The laser is a shining example of how hard it can be to recognize ultimate potential at the point of invention. Unfortunately, that doesn't stop people trying to do so, or trying to pre-empt where research will go. In the run-up to this month's UK general election, the incumbent government had announced a plan to set aside up to $25 \%$ of its science budget to be directed to research that can demonstrate its international impact. What exactly is meant by 'impact', or how this impact will be measured isn't clear certainly not clear enough to convince scientists that it will not be defined only in the crudest economic terms (despite some reassurance to that effect from the science minister, Lord Drayson).

Judging impact is indeed a tricky business, and there is dissatisfaction with present metrics. For example, the Australian National Health and Medical Research Council has announced that it will no longer use journal impact factors in its funding considerations; the Public Library of Science is considering how impact might better be recognized for each individual paper, rather than in a catchall journal-based impact factor.

It can be argued that the scientific pursuit of truth is no less pure a calling than the pursuit of beauty in art; and that to require scientists to justify their quest with the promise of worldly reward is to despoil and corrupt this purity. At the very least, it distracts from a singular curiosity-driven search for truth. However, to suggest that science deserves to be protected from economic reality by right of its intellectual virtue alone is not a winning argument.

Fortunately, the economic argument for strong public investment in science is plain. But there is danger in the spread of popular belief that scientists can know in advance where their curiosity will lead. Maiman didn't, neither did Einstein. No matter how broadly the impact of any given research might be defined, it can only be measured meaningfully in hindsight, sometimes decades after the fact. After all, most research never leads anywhere.

Politicians may claim that investment can only be afforded in science that promises to pay its way. And yet, as the example of the laser shows, it can be disruptive ideas born of the most arcane fields of study that yield the greatest returns.

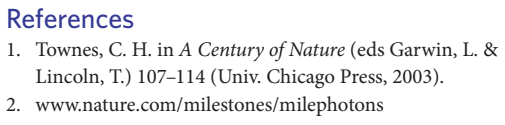

\section{A brief history of photons}

\section{The rich history of research involving photons is celebrated in a supplement to this month's Nature Physics.}

Nature Milestones: Photons is published this month by Nature Physics, Nature Materials and Nature Photonics. In a series of 'Milestone' articles and a collection of relevant research papers from the Nature Publishing Group archive, the supplement recounts the history of research with photons: from the controversy over the wave or particle nature of light and the setting down of Maxwell's equations, through holography and optical fibres to quantum information and metamaterials, to name but a few steps along the way. Of course, the invention of the laser, fifty years ago, is also a significant part of the story.

This is the tenth in the series of Milestones supplements, preceded by others on such topics as spin, light microscopy, DNA

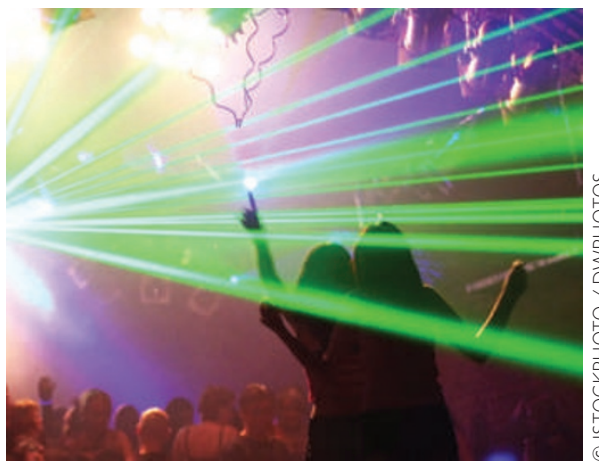

of related breakthroughs) in the context of their time. The aim is to celebrate, in an engaging and concise style, the discoveries and their conceptual beauty, to note earlier achievements and subsequent impact. A comprehensive overview is not intended. After all, the twenty-odd articles cover so many, diverse topics - united as they are by their common theme of 'photons' - that whole books could be (and have been) written on each of them.

We hope you enjoy Nature Milestones: Photons. The Milestone articles are available free online at www.nature.com/milestones/ milephotons (the research collection is free throughout May 2010). Personal subscribers to Nature Physics receive a free copy with the May issue of the journal. 